\title{
IDENTIFYING PRICE DISCRIMINATION WHEN PRODUCT MENUS ARE ENDOGENOUS
}

\author{
Andrew Cohen ${ }^{*}$ \\ Federal Reserve Board of Governors \\ January 2004
}

\begin{abstract}
The standard approach to identifying second degree price discrimination is based on examining correlations between product menus and prices. When product menus are endogenous, however, tests for price discrimination may be biased by the fact that unobservables affecting costs or demand may jointly determine product menus and prices leading one to falsely infer price discrimination. Attempts to correct for this potential bias using observed product characteristics or fixed effects are shown to potentially confound inference on price discrimination leading one to reject it when firms are actually price discriminating. I propose a difference in differences type test that exploits the potential correlation between unobserved product attributes, product menus, and prices.
\end{abstract}

JEL Classification: D4, L0, L1

\footnotetext{
*The opinions expressed in this paper are those of the author and do not reflect those of the Board of Governors or its staff. I am grateful to Phillip Leslie, Mark Manuszak, David Mills, John Pepper, and Robert Porter for many useful discussions and comments. This paper has also benefited from comments by seminar participants at the University of Arizona, Arizona State University, the University of Kentucky, Washington University, and the University of Virginia.
} 


\section{INTRODUCTION}

Over the past several years, economists have attempted to document and characterize examples of second-degree price discrimination in markets with several firms. A pioneering paper in this literature is Shepard [1991], which documents quality-based (i.e., second degree) price

discrimination in a seemingly competitive market (retail gasoline ${ }^{1}$ ). Price discrimination is inferred to the extent that the relationship between product menus ${ }^{2}$ and prices is consistent with the predictions of a model of monopoly price discrimination. This paper confronts a well-known problem in identifying price discrimination - the fact that product menus and prices may be jointly determined by factors unobservable to the econometrician. It has been noted that failing to account for unobserved product characteristics may lead the researcher to infer price discrimination when firms are not price discriminating. I show that the standard approach of conditioning on unobserved product attributes by using firm-level fixed effects may lead the researcher to reject price discrimination when firms are price discriminating. I then propose a testing strategy that, unlike previous work, treats changes in product menus as endogenous. I use a difference in differences approach to determine whether the observed relationship between inter-temporal changes in product menus and prices is consistent with the behavior of a pricediscriminating monopolist choosing both. The paper presents an example of paper towel pricing for different package sizes. Consistent with the arguments above, I find (1) evidence of price discrimination when I ignore unobservable product attributes; (2) evidence against price discrimination when I control for unobservable attributes using fixed effects ${ }^{3}$; and (3) evidence of price discrimination using the difference in differences approach taking changes in product menus to be endogenous.

Many markets are characterized by competing firms each of which offers a menu of goods which differ in a single dimension. Oftentimes these products are sold according to non-linear price schedules. That is, the price per unit of quality or quantity may differ along a firm's product line. Non-linear prices are consistent with second degree price discrimination (or non-linear pricing), but they are also consistent with production costs that vary across qualities or quantities. Without directly observing marginal costs, it is difficult to distinguish between the two explanations. Shepard's insight is to treat differences in product configurations as a natural experiment 
whereby the cost of producing a given quality/quantity variant is independent of the other variants offered on the product menu. Under the price discrimination hypothesis, a good's price depends on the other goods offered in the product line, whereas, under cost-based pricing ${ }^{4}$, the price of a good is independent of the other goods in the product line. In particular, a price discriminating monopolist will charge a higher price for a good if it is sold in conjunction with a lower quality good than if it is sold alone, because marginal consumers can now substitute to the lower quality good (rather than not buying from the firm).

A well-known problem associated with using variation in product menus to test for price discrimination is that product menus are unlikely to be exogenous. The return to offering a longer product line is likely to be increasing in the value of the firm's unobserved attributes (such as a better horizontal location, higher overall product quality, or a more recognized brand name), as is the price of any given product on the firm's line. Therefore, one may observe cross-sectional price differentials (i.e., differences in the prices of products with identical observed characteristics) that are consistent with price discrimination even when firms are not engaging in price discrimination. That is, a firm with more desirable unobserved attributes will likely find it more profitable to offer additional quality variants as well as to charge higher prices - whether it is price discriminating or not.

The standard solution to this problem is to control for differences across firms by including firm characteristics in the estimated pricing equation. In cross-sectional settings (where each firm's product menu and corresponding prices are observed only once) the controls take the form of observable quality characteristics. When time-series or panel data are available, firm fixedeffects are preferred. I show that controlling for firm-level unobservable attributes in this way leads to a different problem. In tests for price discrimination based on the relationship between prices and product configurations, attempts to control for firm effects are likely to reject price discrimination when price discriminating firms with better unobservable attributes not only charge higher overall prices, but also offer larger discounts for their low quality variants.

I therefore develop an alternative test that exploits the fact that predicted price changes resulting from changes in product menus allow one to distinguish price discrimination from cost-based 
pricing (and other alternative hypotheses). This difference in differences approach eliminates the cross-sectional comparisons that confound inference in existing tests. I suggest comparing price changes for a particular product for a given firm over time when (1) new variants have been added to a firm's product menu, (2) existing variants have been removed from a firm's product menu, and (3) no changes have been made to the firm's product menu. Itoh's [1983] model of a price discriminating monopolist suggests that it is profitable for firms to add lower quality products to their menus when it allows them to increase the price of existing higher quality goods. This prediction is the basis of the proposed test.

The empirical application to package sizes of paper towels lends support to the claims above. Incporating results from Gerstner and Hess [1987], I treat smaller sized packages of paper towels as higher quality goods (since they are easier to transport and store than larger sizes). The relationship between prices and product menus suggests that firms are price discriminating when minimal controls for unobservabled product attributes are used, while price discrimination is rejected when finer controls for unobserved product attributes (in the form of more specific fixed effects) are used. Using the difference in differences approach, however, I find evidence that manufacturers introduce larger paper towel sizes when it allows them to increase the prices of smaller sizes, which is consistent with the behavior of a price discriminating monopolist.

The paper is organized as follows. Section 2 reviews some theoretical and empirical papers on second degree price discrimination. Section 3 proposes a standard test of quality based price discrimination for the paper towel industry. Section 4 presents results from the test, using fixed effects to control for the potential endogeneity of product menus. I show that this approach may lead one to reject price discrimination when firms are price discriminating. In section 5, I propose a new test for price discrimination that exploits the joint determination of product menus and prices using a difference in differences approach. Section 6 concludes. 


\section{THEORETICAL AND EMPIRICAL PAPERS ON SECOND DEGREE PRICE DISCRIMINATION}

Theoretical models of monopoly price discrimination (both second and third degree) have been extensively studied, and there is a growing literature on price discrimination in oligopolistic settings. Equilibria in which pricing behavior that is more or less consistent with monopoly price discrimination have been shown to be sustainable. Depending on the assumptions of the models, prices converge away from those that would be set by price discriminating local monopolists at various rates as more firms enter the market. Stole [1995] shows that second degree price discrimination is sustainable in a multi-firm setting where consumers have preferences over a brand's horizontal location as well as the (vertical) quality of the goods in a given brand's menu, and preferences in one of the dimensions are private information. As more brands enter the market, pricing behavior continuously tends away from the monopoly case. Armstrong and Vickers [2001] and Rochet and Stole [2002] show that when both horizontal and vertical preferences are private information, "competitive price discrimination" (i.e., first best product menus priced at cost plus constant markup with no monopoly distortion) is a possible outcome. The tests discussed in this paper focus on whether observed pricing behavior (for a given brand) is consistent with price discrimination by a local monopolist.

Shepard [1991] studies quality based price discrimination by service stations in the Boston area. She derives predictions from a model in which each firm has local market power (corresponding to, among other things, brand differentiation) allowing one to consider each firm's decision in isolation. Under the price discrimination hypothesis, a larger price is expected for full service gasoline at a multi-product station (that offers both full and self service) as opposed to a singleproduct station that offers full service only. On the other hand, a lower price is expected for self service gasoline at a multi-product station as opposed to a single-product station that offers self service only. Multi-product stations charge a higher price for the high quality good (i.e., full service) because marginal consumers can substitute to the low quality good (self service). In addition, multi-product stations charge a lower price for the low quality good since they have fewer inframarginal consumers (given the existence of a high quality good) than single product stations. Shepard's argument is based on the assumption that the cost of offering both full and 
self-service gasoline is independent of the product menu (whether the station is single or multiproduct), and that the distribution of consumers purchasing from single and multi-product stations is identical. Thus, variation in prices that is correlated with variation in the product menu (in particular, higher full-service and lower self-service prices at multi-product stations) is taken as evidence of price discrimination. Manuszak [2001] finds similar results for the Hawaii gasoline market.

Other papers have investigated the effect of competition on price schedules. Busse and Rysman [2003] study the effect of competition on the curvature of firms' pricing schedules for yellow pages advertising. They find that firms facing less competition tend to disproportionately raise prices on higher quality goods ${ }^{5}$, leading to larger discounts on lower quality goods. Borenstein and Rose [1994], in a study of third degree price discrimination, examine the effect of competition on the pricing schedules of airlines. There have also been several papers employing structural models to assess the welfare consequences of second degree price discrimination. ${ }^{6}$ The advantage of these structural models is the ability to answer a richer set of questions at the cost of making much stronger underlying assumptions. ${ }^{7}$

\section{A TEST FOR QUALITY-BASED PRICE DISCRIMINATION IN THE PAPER TOWEL MARKET}

\section{Data}

More than 50 brands of paper towels (including generics and private labels) were marketed in the United States from 1994 to 1998 . All but two of the top ${ }^{8}$ seventeen brands sold during this period belong to one of the following firms: Fort James Corporation (the result of an August 1997 merger of Fort Howard Corporation and James River Corporation); Georgia Pacific Corporation; Kimberly Clark Corporation (which merged with Scott Paper in July 1995); and Procter and Gamble. In addition to branded paper towels, private label (i.e., towels sold under the name of the grocery store) and generic paper towels comprise a substantial quantity (approximately onefourth) of total paper towel sales. 
The sample used in this study comes from data compiled by Information Resources Incorporated (IRI). The data have been compiled for 64 cities over twenty quarters from 1994 through 1998. Each city/quarter combination represents a "market." For each product (i.e., brand/size combination), therefore, there are 1280 potential markets in which the good could have been sold. ${ }^{9}$ IRI's sample is collected from grocery stores ${ }^{10}$ with sales greater than $\$ 2$ million per year. ${ }^{11}$ A product corresponds to a brand and a package size, where size refers to the number of rolls contained in the package. The number of rolls in a package seems to be the best proxy of "bulkiness" which will affect consumer preferences as well as manufacturing costs. I observe the average price in the market for each product sold.

\section{Underlying Assumptions}

\section{A. Manufacturer Behavior}

For ease of exposition, I assume that retail prices are the result of a data generating process that is observationally equivalent to the practice of resale price maintenance by paper towel manufacturers. ${ }^{12}$ This assumption is valid if one believes that retailers either apply constant markups ${ }^{13}$ or manufacturers influence retail prices for their products. There is some anecdotal evidence that the latter is true. Paper towel manufacturers have representatives that call on grocery chains' regional purchasing managers. They are permitted to ask for "price parity" or degrees of "price competitiveness" with other brands, though they are not allowed to name prices. This assumption, which allows me to consider only the role of the manufacturer, has been made by others using similar data. ${ }^{14}$ In addition to abstracting from the relationship between manufacturers and retailers, I also abstract from "portfolio effects" on the part of manufacturers. That is, I treat each brand as a local monopolist (similar to Shepard and Nevo and Wolfram [2002]). ${ }^{15}$

Production costs associated with a particular package size are permitted to vary across sizes. For a particular package size, however, production costs are assumed constant over quantity produced and independent of the other sizes offered by a given brand. That is, it is assumed that there are no economies of scope or scale. ${ }^{16}$ 


\section{B. Package Size as Quality}

Gerstner and Hess [1987] show that quantity discounts can arise in an environment where consumers incur transaction and storage costs. Smaller packages may correspond to either higher or lower quality. ${ }^{17}$ When quantity discounts (as observed with paper towels) are optimal, smaller packages are shown to correspond to higher quality. ${ }^{18}$ Quality (which is not directly observed) discounts may or may not be offered.

I assume that consumers at least weakly prefer smaller package sizes due to the convenience they provide in reducing transportation and storage costs. ${ }^{19}$ In addition, consumers who are budget constrained may prefer to make purchases for smaller absolute dollar amounts (even if they pay a unit price premium) in which case they would prefer smaller package sizes. Therefore, one may choose to think of package size as a matter of convenience - i.e., as a dimension of product quality.

\section{Test Setup}

I propose a test similar to Shepard's, using package sizes instead of service grades. Every paper towel brand in the sample always offers one-roll packages, which are assumed to be the highest quality variant. Therefore, the variation in product offerings that I exploit must be in the other sizes. I test whether the price of a given size depends on whether or not it is the largest size sold by the brand (i.e., the lowest in relative quality) in the particular market. Essentially, I test whether there is an effect to being the largest size that is independent of the absolute size of the product. Consistent with Shepard's analysis, whether or not a given size is the largest offered by the brand should not affect the cost of offering that size, but will, under the hypothesis of price discrimination, result in a lower price than if a larger size were also offered.

Due to the fact that all brands offer small sizes, I am essentially left with half of the "natural experiment" that Shepard had - i.e., it is as if Shepard observed full-service only and multi-

product stations, but no self-service only stations. ${ }^{20} \mathrm{I}$ am able, however, to exploit additional variation due to the panel nature of the data, which allows me to use within-brand variation in 
product offerings to identify the effect of being the largest size sold and to gain insight into the extent to which brand (and/or market) level unobservables may be biasing the results.

\section{Alternative Behavioral Hypotheses}

Inferring whether or not firms practice second degree price discrimination depends upon identifying factors that affect prices if a firm is price discriminating, but do not affect prices (or do so in the opposite direction) under alternative hypotheses. I focus on two alternative hypotheses that could explain quantity discounts in paper towels, and discuss how price discrimination can be separately identified from these explanations.

\section{A. Cost Economies}

Non-linear prices may exist due to non-linearities in costs, without the presence of price discrimination. ${ }^{21}$ This will be the case if: (1) the market is competitive; or, (2) manufacturers charge cost-plus markup. ${ }^{22}$ There are, in fact, reasons to believe that costs vary with the number of rolls in a package in which case cost-based pricing could be consistent with the price data. Production efficiencies (i.e., economies of scale in package size) on larger sized packages may exist; it may also be the case that distribution, inventory or transactions costs are lower for larger

sized packages. Anecdotal evidence is somewhat mixed on this point. In informal interviews ${ }^{23}$, a public relations representative from one of the major manufacturers described quantity discounts as merely "passing along our cost savings to the consumer," while a marketing representative from another major manufacturer told a story more consistent with price discrimination. Finally, a sales representative from an industrial paper products distributor claimed that costs explained quantity discounts for towels sold in grocery stores (the object of this study), but not for industrial paper towels. ${ }^{24}$

\section{B. Independent Sub-Markets}

Demand may be independent across package sizes. That is, consumers who purchase six-roll packages may never substitute to three-roll packages - i.e., the two sizes constitute entirely different markets. The fact that one size is more expensive than another would then be due to 
differences in the elasticities of demand in each size market, and not because firms are inducing consumers to purchase one or the other of the sizes to extract additional surplus.

\section{Biases due to Endogenous Product Menus}

Inferring price discrimination from a negative price effect associated with being the largest size that the brand offers is troublesome if one believes that product offerings are not exogenous. It is therefore worth discussing what effect endogenous product menus have on the validity of this test. That is, what could be causing the observed variation in the number of sizes offered by firms, and how would one expect this variation to affect prices? In particular, I consider the manner in which unobservables related to a brand's cost structure or demand characteristics might generate results that are consistent with price discrimination even when firms are not price discriminating.

A monopolist's variable profit is weakly increasing in the number of goods offered. The existence of finite product menus suggests fixed costs associated with offering additional sizes. Assuming that fixed costs in a given market are increasing in the number of sizes, both cost or demand unobservables could explain the variation in observed product menus (in particular, number of sizes offered). I consider each in turn, and discuss the extent to which unobserved product attributes could lead one to infer price discrimination when in fact, prices are cost based or demands are independent across sizes.

\section{A. Cost Unobservables}

Cost unobservables include differences in both fixed and variable costs (across either brands or markets - though I focus my discussion on markets). If fixed costs differ across markets, markets with higher fixed costs per size, will have fewer products offered. Variation in fixed costs, however, should not affect firms' pricing decisions since the variable profit function does not depend upon fixed costs. Shifts in variable costs that are specific to a particular size, however, could conceivably generate the predictions made by the model of price discrimination. For example, if medium sizes are cheaper to produce than large sizes in market A, but not in market $\mathrm{B}$, one might observe only small and medium sizes sold in market A, and small, medium and 
large sizes sold in market B. Under cost-based pricing, one would expect the medium price to be lower in market $\mathrm{A}$ due to cost differences rather than price discrimination. If costs are weakly monotonic in package size, however, this will not be a problem.

\section{B. Demand Unobservables}

Unobservables affecting demand for a particular brand are more problematic. Suppose that demands are independent across sizes but that the popularity of a particular brand is consistent across size submarkets - e.g., if Bounty is the most popular brand in the market for three roll packages it is also the most popular brand in the market for six roll packages (though there is no interaction between the two markets). Brands with better overall quality will choose to offer more sizes (since their variable profits will be higher in each size submarket that they enter); they will also be able to charge higher prices. Without controlling for brand quality, the proposed test would fail to reject price discrimination if the hypothesis of independent demands were in fact true. Consider a market in which Brand A has higher quality than Brand B. Because of this, A offers three sizes and B offers 2 sizes. For the same reason it offers more sizes, A also charges higher prices in the segments in which it competes with B. Under the test discussed above, price discrimination would be inferred when, in fact, the size segments are independent. One could similarly argue that price discrimination might be incorrectly inferred if unobserved product quality is costly and pricing is cost-plus. The use of brand fixed effects (possibly interacted with market and time fixed effects) has been suggested as a remedy for this type of bias.

\section{RESULTS FROM STANDARD TEST}

To test the prediction that being the largest size sold has a negative effect on price, independent of the absolute size of the good, I estimate a reduced-form pricing equation. Each observation corresponds to a product that is characterized by a brand, B, a package size, S, a city, C, and a quarter, T. The estimated pricing equation is:

(1) $\ln P_{B, S, C, T}=\beta$ Largest $_{B, S, C, T}+f\left(S_{B}\right)+\Theta_{B, C, T}+\varepsilon_{B, S, C, T}$ 
where LARGEST is equal to one if the product is the largest product of its brand offered in the market (i.e., city/quarter combination) and zero otherwise, $f$ is a function of package size (and is allowed to vary across brands in some of the specifications), $\Theta$ is a vector of fixed effects, and $\varepsilon_{B, S, C, T}$ is a mean zero error term assumed to be independent of the regressors.

The intuition underlying the test is that a product that is the largest size of a particular brand should be discounted more heavily than an identically sized product which is not that brand's largest size, if firms are price discriminating. Table I presents the estimated effect of being the largest size in a brand's menu conditional on the absolute size, i.e., number of rolls. Each entry in the table corresponds to an estimated $\beta$, depending on the specification. Specifications differ by the fixed effects used, and by the manner in which absolute size enters equation 1. Different specifications for $f(\mathrm{~S})$ correspond to the columns of Table I, while different fixed effects correspond to the rows. The controls for absolute size, going across the columns, are (1) number of rolls; (2) number of rolls, by brand; (3) dummies for each size; and (4) dummies for each size, by brand.

The effect of using different controls for unobserved product, i.e., different fixed effects, is seen in the differences in the estimated effect of being the largest size going down the rows of each column. The first row contains fixed effects for each market (i.e., city-quarter combination) thereby identifying the effect of being the largest size primarily from cross-sectional variation. That is, I only control for market-level unobservables, with no controls across brands within a market. Consistent with price discrimination, I find a large statistically significant negative effect associated with being the largest size offered ranging from approximately five to twelve percent. ${ }^{25}$ When I add brand fixed effects, in the second row, to control for differences in the unobserved quality of different brands, the result is reversed and I reject price discrimination with the effect of being the largest size being small, positive, and precisely measured.

I obtain similar results when I start with minimal fixed effects and proceed to add finer controls as seen in the lower two-thirds of Table I. In particular, with no fixed effects or fixed effects for either brand, city or quarter only, I find a negative and statistically significant effect associated with being the largest size of a brand (regardless of how I condition on actual size). Once I add 
brand fixed effects in (any) combination with city and quarter, however, the effect of being the largest size is estimated to be positive (though small in magnitude) and often statistically significant.

\section{Bias due to Attempting to Control for Unobserved Attributes}

The results above suggest that paper towel manufacturers do not set prices in a manner consistent with monopoly price discrimination. It is possible, however, to rationalize these empirical results in a manner that is consistent with the practice of quality-based price discrimination. While it is true that failing to control for unobserved product attributes can lead one to infer price discrimination falsely, I show that controlling for unobservables using fixed effects can lead one to reject price discrimination falsely.

Consider the following example in which firm A has better unobserved attributes than firm B, and therefore extends its product menu to three sizes (as opposed to B who offers two sizes). If both firms are price discriminating, and $\alpha, \delta, \gamma>0$, then equilibrium prices will have the following form.

\begin{tabular}{|l|c|c|}
\hline & Brand A & Brand B \\
\hline Price of Small Size & $P_{A}$ & $P_{B}$ \\
\hline Price of Medium Size & $P_{A}-\delta$ & $P_{B}-\gamma$ \\
\hline Price of Large Size & $P_{A}-\delta-\alpha$ & Not offered \\
\hline
\end{tabular}

Based on equation 1, including a fixed effect for each brand and a fixed effect for each size, the effect of being the largest size of a brand is $\delta-\gamma$. If Brand A offers at least as large a discount as Brand B for its medium size, I would reject price discrimination even though the data are consistent with a model in which both brands price discriminate, and Brand A has better quality. 
If firms are price discriminating, and firms with better unobserved attributes offer larger discounts on lower quality variants, the use of fixed effects to "control" for unobservables will lead one to falsely reject price discrimination. Another way of thinking about this condition is that one will erroneously reject price discrimination if firms with better unobserved attributes tend to apply proportionally higher markups on their higher quality (i.e., smaller sized) variants. Unobserved attributes in this context, may correspond to unobserved quality, or other omitted variables such as differences in the degree of competition faced by each firm.

Larger discounts by price discriminating firms with better characteristics or greater market power have been suggested in both theoretical and empirical papers. Stole [1995] and Rochet and Stole [2001], for example, show that the price dispersion across qualities decreases as more firms enter the market. In an empirical paper, Busse and Rysman [2003] find relatively larger markups for bigger $^{26}$ advertisements in Yellow Page directories when firms have greater market power.

\section{A. Empirical Support for Bias}

I find support for this argument in the paper towel industry as well. In particular, I compare the price schedules of branded and unbranded paper towels to determine whether branded paper towels have steeper price schedules. I consider whether or not a towel is branded as a (gross) structural proxy for its quality and market power. In particular, unbranded paper towels have substantially less market power than branded paper towels. This is due to the fact that (1) unbranded paper towels are less differentiated than their branded counterparts (both because they have not been advertised and because there are so many of them) and, (2) manufacturing of unbranded paper towels is extremely competitive (there were at least twelve manufacturers of unbranded paper towels in the United States as of $1991^{27}$ ). If the relative difference between the discounts (from one-roll packages) offered by branded and unbranded paper towels are increasing in package size, one might infer that more differentiated brands tend to offer larger discounts for lower quality variants. This would suggest that unobserved product attributes may be biasing the test discussed above, and would rationalize the results of the test in a manner that may still be consistent with price discrimination. 
I use supplemental data on private label prices to investigate whether more differentiated products offer larger discounts on lower quality variants. I divide paper towels into four size categories: 1-rolls; 2 and 3-rolls; 6-rolls; and 8-rolls or more. Table II presents the 95 percent confidence intervals for the difference between the percentage discount offered by branded and unbranded paper towels for each size group, relative to 1-rolls.

Table II indicates that branded paper towels offer larger discounts for bigger package sizes. In addition, the relative differences between quantity discounts offered by branded and unbranded paper towels is increasing in package size. This lends support to the claim that the fixed effects may be confounding inference on price discrimination since, it appears, that more differentiated brands (at least using this crude proxy for differentiation) do discount their larger sizes more than the less differentiated brand. ${ }^{28}$ Conversely, it appears that more differentiated brands mark up their higher quality (lower sized) variants relatively more than the less differentiated brand.

Given the possibility that the test discussed above may be rejecting price discrimination falsely, I turn my attention to developing a test that is robust to this critique. My strategy is to accept that product menus are, to some extent, endogenously determined. I then ask whether changes in prices following changes in a brand's product menu are consistent with the behavior of a price discriminating firm who chooses both its product menu and price schedule.

\section{PRICE DISCRIMINATION WITH ENDOGENOUS PRODUCT MENUS}

\section{Changes in Product Menus over Time}

Brands make relatively few changes to the menu of variants they offer in a particular geographic market. Often, a brand will choose to go several periods without changing its menu, then introduce a new size or withdraw an existing size in one period, and then continue for several more periods without changing its menu. Table III presents the frequency with which each brand in the sample chose to introduce a new size, remove an existing size, or keep its menu the same, 
across its geographic markets. ${ }^{29}$ As is evident from the table, changes in a brand's product menu within a city occur anywhere from seven percent to thirty percent of the time.

Firms may choose to change their product lines if they are price discriminating, but also under the alternative hypotheses. Cost shocks may make certain sizes more or less profitable leading to changes in the product menu. Demand shocks - such as an increase or decrease in the brand's perceived quality - may do the same when demands are independent across sizes but the popularity of a particular brand is consistent across sizes. Finally, both cost and demand shocks may change the optimal size menu of a price discriminating firm. However, changes in the product menu will have a different effect on prices under each of the three behavioral hypotheses allowing me to use variation in product menus to construct an alternative test for price discrimination. Before considering the effect of changes in the product menu on prices under each hypothesis, I first address the timing of firms' decisions.

\section{A. Timing of Decisions}

It is most straightforward to assume that changes to a brand's size menu take time to affect, whereas price changes can be made quickly in response to permanent shocks to either cost or demand. ${ }^{30}$ In particular, I assume that using the information available at time $t$, the firm chooses (1) a price schedule for $t$, given the brand's size menu; and (2) whether or not to change its size menu in the next period, $t+1$. The choice of whether or not to change the product menu will depend on whether the firm expects a menu change to yield larger profits than the existing menu, in $t+1$. If firms were perfectly informed, each would know exactly what prices it would charge in $t+1$ if it chose to change its menu. Due to unanticipated shocks in cost and demand, however, the firm must form an expectation of the price it will charge for each product in $t+1$. The predictions I derive under the various hypotheses focus on how much the firm expects the prices of its other products to change following the introduction or removal of a product. I use the actual price change, $P_{t+1}-P_{t}$ as an estimate of the firm's time $t$ expectation of the inter-temporal price change, i.e., $E_{t}\left[P_{t+1}-P_{t}\right]$. This will be an unbiased estimate as long as any unanticipated shocks that occur after the menu has been chosen for $t+1$ are uncorrelated with the product menu in $t+1$. 


\section{B. Predictions}

A brand may choose to expand its product menu in period $t+1$ for two reasons. First, the brand's permanent costs (either fixed or variable) may have decreased ${ }^{31}$ making it more profitable to add another size (under any of the competing hypotheses). Second, perception of the brand's quality or its ability to differentiate itself may have improved making additional products more profitable than they had been in the past. If the firm faced exactly the same conditions in $t$ and $t+1$, then under cost-driven pricing, the firm would charge exactly the same price in $t+1$ after the introduction of the new product variant as it did in $t$. Similarly, if demands were independent, the firm would charge the same prices in $t$ and $t+1$.

I derive predicted price changes for a price discriminating monopolist using arguments from Itoh [1983]. Itoh considers a model in which a price discriminating monopolist (for whatever reason) is not offering the optimal product menu in $t$, but makes an improvement to the menu (either by adding or removing a variant) in $t+1$. The demand and cost structures in the two periods are identical. Given the assumed timing of decisions, my model is identical to Itoh's. ${ }^{32}$ I use his results to describe the expected price differential for those package sizes sold in both $t$ and $t+1$. The model is identical to that of Mussa and Rosen, but with a discrete number of goods.

Itoh shows that introducing a new variant or removing an existing variant of size $s_{k}$ has no price effect for all lower quality variants (i.e., $s_{k+1}, s_{k+2}, \ldots$ ). However, it does affect the prices of all higher quality variants (i.e., $s_{k-1}, s_{k-2}, \ldots$ ) similarly; either all products experience price increases, no change, or price decreases. The direction of the effect depends on the shape of the hazard $[F(t) / f(t)]$ over the range of consumers purchasing the new variant $s_{k}$. If the market for the newly introduced(withdrawn) good is smaller than the markets for the higher quality goods, then the prices of the higher quality goods increase(decrease). This condition would suggest that adding a package size should increase the price of smaller sizes, and dropping a size should decrease the price of smaller sizes since one-rolls (which are never added or dropped) are generally the largest market segment for each brand.

To take these predictions to the data, I ask whether inter-temporal price changes for products where the menu has changed (i.e., another product has been added or removed) are comparable 
to price changes for products where the product menu has remained constant. Let $P_{t}(1), P_{1}(-1)$, and $P_{t}(0)$ represent the prices of a product for which a larger size (lower quality) product is to be added in $t+1$, a larger size product is to be removed in period $t+1$, and a larger size product is neither to be added nor removed in $t+1$, respectively. Firms' expectations about their own price changes from $t$ to $t+1$ under the different hypotheses are summarized below:

\begin{tabular}{|c|c|c|}
\hline Hypothesis: & $\begin{array}{l}E_{t}\left[P_{t+1}(1)-P_{t}(1)\right] \\
-E_{t}\left[P_{t+1}(0)-P_{t}(0)\right]\end{array}$ & $\begin{array}{l}E_{t}\left[P_{t+1}(-1)-P_{t}(-1)\right] \\
-E_{t}\left[P_{t+1}(0)-P_{t}(0)\right]\end{array}$ \\
\hline Price Discrimination & Positive & Negative \\
\hline Cost-Based Pricing & 0 & 0 \\
\hline Independent Demands & 0 & 0 \\
\hline
\end{tabular}

Assume that prices for product $i$ can be expressed as follows:

(2) $\quad P_{i, t+1}(z)=E_{t}\left[P_{i, t+1}(z)\right]+\eta_{i, t+1}$

where $\eta_{i, t+1}$ captures the portion of the price at $t+1$ that the firm could not anticipate given its information at time $t$. By definition, $E\left[\eta_{i, t+1} \mid z\right]=0$. This implies that the actual price change is a valid proxy for the price change that the firm anticipated when it chose its product menu for $t+1$. This suggests that the relationship between inter-temporal price and product menu changes can be used as the basis to test the predictions in the table above.

\section{Results}

In order to determine whether price changes following changes in the product menu are consistent with price discrimination I estimate the following equation:

(3)

$$
\begin{aligned}
\frac{P_{i, t+1}-P_{i, t}}{P_{i, t}}= & \Theta+\alpha_{1} \text { ANYADDED }_{i, t+1}+\alpha_{2} \text { ANYDROPPED }_{i, t+1} \\
& +\beta_{1} \text { LGADDED }_{i, t+1}+\beta_{2} \text { LGDROPPED }_{i, t+1}+\varepsilon_{i, t+1}
\end{aligned}
$$


where $\Theta$ is a vector of fixed effects which will vary across specifications and the remaining variables are defined as follows

ANYADDED Dummy variable equal to one if $i$ 's brand introduced a new product in $i$ 's market in $t+1$, equal to zero otherwise

LGADDED Dummy variables equal to 1 if if $i$ 's brand introduced a new product in $i$ 's market in $t+l$ that was larger than $i$, equal to zero otherwise

ANYDROPPED Dummy variable equal to one if $i$ 's brand removed a product in $i$ 's market in $t+1$, equal to zero otherwise

LGDROPPED Dummy variable equal to one if $i$ 's brand removed a product in $i$ 's market in $t+1$ that was larger than $i$, equal to zero otherwise

If firms are price discriminating in a manner consistent with Itoh's model, then $\beta_{1}$ should be positive and $\beta_{2}$ should be negative. In addition, $\alpha_{1}$ and $\alpha_{2}$, which represent the expected price change if a product is larger than the newly introduced or removed product, should be equal to zero. The $A N Y A D D E D$ and $A N Y D R O P P E D$ variables are important for ruling out the presence of independent sub markets. Suppose that firms can add products whenever they wish (rather than having to wait a period). One could then argue, for example, that a firm added a product in period $t+l$ because it received a beneficial shock in $t+1$. If the size submarkets are independent, the firm will increase the prices of all sizes in response to the shock, in addition to adding a size. Including the variable $A N Y A D D E D$ allows me to distinguish between price discrimination (in which case only the prices of sizes smaller than the newly introduced size would increase) and pricing with independent demands (in which case, the prices of all sizes would increase).

Table IV provides estimates of the $\alpha$ 's and the $\beta$ 's. The fixed effects are extremely important for interpreting the results in Table IV. For example, the first column of Table IV contains results from a specification with brand fixed effects. In this case, $\beta_{1}$, the coefficient on $L G A D D E D$ measures the average (across all brands) difference in inter-temporal price changes associated 
with having a larger product introduced relative to products of the same brand for which a smaller (not larger) product was introduced. The average (across all brands) difference in intertemporal price changes associated with having a larger product introduced relative to products of the same brand for which no product was either introduced or removed, is given by $\alpha_{1}+\beta_{1}$. (The difference between these two effects, i.e., $\alpha_{1}$, is not statistically significant at the $10 \%$ level in any of the specifications.)

The empirical results in Table IV suggest that when firms add products they do so for reasons that are consistent with price discrimination and inconsistent either with cost-based pricing or pricing with independent demands. In every specification, the effect of adding a larger product is both economically and statistically significant. The average price increase for products in which a larger size has been added in the current period is between 2 and 2.8 times as large as the average price increase of the other products in the reference group for which a larger size has not been added - depending on the reference group. On the other hand, there is virtually no effect associated with dropping a size. The effects are quite small in magnitude and measured imprecisely.

One the whole, the estimates suggest that paper towel manufacturers choose to extend their product menus in manner consistent with the behavior of a price discriminating firm. That is, introducing a new variant increases the prices of a brand's higher quality variants more than both (1) lower quality variants of the brand sold in the same market and (2) all variants in markets in which there were no changes in the product menu. When firms remove existing products, however, the results are consistent with any number of behavioral hypotheses. ${ }^{33}$ Evidence of price discrimination based on changes in prices that are correlated with the introduction of new variants is nonetheless more compelling than the evidence one can provide by treating product menus as exogenous, or by trying to control for endogeneity by controlling for brand-level effects. It is precisely the correlation between the decision to change the product menu and the price schedule that allows me to distinguish price discrimination from the alternatives. Had I treated product menus as exogenous and simply attempted to control for unobserved attributes using fixed effects, I would have rejected price discrimination even though there is significant evidence that firms do indeed price discriminate. 


\section{CONCLUSION}

This paper addresses the identification of price discrimination in general, and also contributes to the study of the use of product packaging as mechanism for sorting consumers. The main empirical finding of the paper is that there is significant evidence that paper towel manufactures price discriminate by offering different package sizes at different unit prices. I am able to distinguish price discrimination from the two most plausible alternative hypotheses: cost-based pricing, and pricing with demands that are independent across size segments. The main contribution of the paper, however, is to show that tests for price discrimination that treat product menus as exogenous and try to control for unobserved product attributes are generally not able to distinguish price discrimination from these alternative hypotheses. It is well-known that failing to control for unobserved differences between brands may result in biased tests for price discrimination (i.e., one may find evidence of price discrimination when demands for different qualities are actually independent). Controlling for these unobserved differences using level fixed effects, however, is shown to erode the power of the same tests in the sense that one is likely to reject price discrimination when firms are price discriminating. My solution is to treat product menus as endogenous and to derive a test (based on firms' decisions to introduce a new product or remove an existing product) that is capable of distinguishing price discrimination from the alternatives. The empirical results of this test, unlike my adaptation of existing tests, are robust across specifications and provide significant evidence for the existence of quality-based price discrimination. 


\section{REFERENCES}

Armstrong, M. and Vickers, J. "Competitive Price Discrimination." Rand Journal of Economics, 32 (2001): 579-605.

Borenstein, S. and Rose, N. "Competition and Price Dispersion in the U.S. Airline Industry." Journal of Political Economy, 102 (1994): 653-683.

Busse, M. and Rysman M. "Competition and Price Discrimination in Yellow Pages Advertising.” Mimeo, Yale University, 2003.

Clerides, S. "Product Selection with Multi-Peaked Preferences in Book Publishing." Mimeo, University of Cyprus, 2001.

Cohen, A. "Package Size and Price Discrimination in Paper Towels," Mimeo, University of Virginia, 2000.

Gerstner, E. and Hess, J. "Why Do Hot Dogs Come in Packs of 10 and Buns in 8s or 12s? A Demand Side Investigation.” Journal of Business, 60 (1987): 491-517.

Halvorsen R. and Palmquist P., "The Interpretation of Dummy Variables in Semilogarithmic Regressions," American Economic Review, 70 (1980): 474-475.

Itoh, M., Monopoly, "Product Differentiation and Economic Welfare," Journal of Economic Theory, 31 (1983): 88-104.

Leslie, P. "Price Discrimination in Broadway Theatre," Rand Journal of Economics, forthcoming.

Lott, J. and Roberts, R. “A Guide to the Pitfalls of Identifying Price Discrimination,” Economic Inquiry, 29 (1991): 14-23.

Manuszak, M. "Price Discrimination in the Hawaiian Retail Gasoline Industry," Mimeo, Carnegie Mellon University, 2001.

Maskin, E. and Riley J. "Monopoly with Incomplete Information," Rand Journal of Economics, 15 (1984): 171-196.

McManus, B. "Nonlinear Pricing in an Oligopoly Market: The Case of Specialty Coffee," Mimeo, Washington University, 2003.

Mussa, M. and Rosen, S. "Monopoly and Product Quality," Journal of Economic Theory, 18 (1978): 301-317.

Nevo, A. "Mergers with Differentiated Products: The Case from the Ready-to-Eat Cereal Industry." Rand Journal of Economics, 31 (2000): 395-421 
Nevo, A. "Measuring Market Power in the Ready-to-Eat Cereal Industry," Econometrica, 69 (2001) 307-342.

Nevo, A. and Wolfram, C. "Why do Manufacturers Issue Coupons? An Empirical Analysis of Breakfast Cereals," Rand Journal of Economics, 33 (2002): 319-339.

Rochet, J. and Stole, L. "Non-Linear Pricing with Random Participation Constraints." Review of Economic Studies, 69 (2002): 277-311.

Shepard, Andrea. "Price Discrimination and Product Configuration," Journal of Political Economy, 99 (1991): 30-53.

Stole, L. "Nonlinear Prices and Oligopoly," Journal of Economics and Management Strategy, 4 (1995): 529-562.

Verboven, Frank, "Quality Based Price Discrimination and Tax Incidence - Evidence from Gasoline and Diesel Cars," Rand Journal of Economics, 33 (2002): 275-297. 
${ }^{1}$ Levels of service, full and self-serve, represent different qualities.

${ }^{2}$ Product menus correspond to levels of service offered, i.e., full and self.

${ }^{3}$ As shown below, this finding has nothing to do with the loss of degrees of freedom associated with using fixed effects.

${ }^{4}$ Cost-based pricing encompasses perfect competition as well as cost plus a constant markup.

${ }^{5}$ In this case, higher quality goods correspond to larger sized advertisements.

${ }^{6}$ See, for example, Clerides [2002], Cohen [2000], Leslie [2004], McManus [2003], and Verboven [2002].

${ }^{7}$ Among these assumptions is that firms are price discriminating in the first place.

${ }^{8}$ In terms of market share, conditional on being offered.

${ }^{9}$ In fact, not all brands are sold in all cities. In addition, many package sizes are sold only in a few cities.

${ }^{10}$ The dataset excludes large "clubs" like Sam's Club and Costco, as well as convenience stores like 7-Eleven and White Hen.

${ }^{11}$ IRI says this comprises more than eighty percent of grocery sales in the US, and more than $20 \%$ of the relevant sample in most markets. As reported in Nevo [2000], unofficial Bureau of Labor Statistics reports suggest that the sample is representative.

${ }^{12}$ In principle it should not matter if manufacturers are not involved in setting retail prices. The principal difference would be in the interpretation of who is doing the price discriminating, and the plausibility of the assumption that portfolio effects (discussed below) are of second order importance.

${ }^{13}$ Even if markups differ across brands or sizes, the assumption is valid. If, however, markups differ across brand/size combination, one would have to additionally assume that manufacturers know the fixed markup for each good.

${ }_{14}^{14}$ See Nevo [2000 and 2001] and Nevo and Wolfram [2002], for example.

${ }^{15}$ Evidence from Cohen [2000] suggests that brand-level pricing is consistent with the data.

${ }^{16}$ These assumptions may not be required if a sufficient number of fixed effects are employed in the empirical specification. I make the assumptions, however, for ease of exposition.

${ }^{17}$ This depends upon the degree of consumer hetereogeneity in both storage and transactions costs.

${ }^{18}$ This is different from Maskin and Riley [1984], who show that quantity discrimination is isomorphic to quality discrimination where larger quantities of a good are the same as a higher quality good.

${ }^{19}$ Since a consumer can always compose a larger size from one-roll sizes it stands to reason that even consumers who do not value package size at all, would be indifferent between a one-roll and any other size, at identical unit prices.

${ }^{20}$ The most compelling evidence of price discrimination in Shepard, however, is that offering self-service increases the premium on full service (which is analagous to my proposed test). Offering full service does have a negative, but small and statistically insignificant, effect on self service prices.

${ }^{21}$ That is, all differences in prices across package sizes of the same brand may be cost differences. The existence of cost differentials as an explanation for pricing differentials is a standard defense against claims of price discrimination. See, for example, Lott and Roberts [1991].

${ }^{22}$ Cost-plus pricing is also a possible outcome of "competitive price discrimination" in an oligopoly as described by Rochet and Stole [2002] as well as Armstrong and Vickers [2001]. The theoretical conditions under which cost-plus pricing is an equilibrium outcome of price discrimination are not satisfied in the paper towel industry. In any event, rejecting cost-based pricing also rejects this particular outcome of price discrimination.

${ }^{23}$ The last of which was conducted as the result of a chance meeting on an airplane while the author was en route to deliver a previous version of this paper.

${ }^{24}$ Whether or not one takes the cost explanations for quantity discounts in paper towels is reasonably unimportant in this study. The prior belief that package size discounts for paper towels must be the result of price discrimination should only serve to bolster the importance of the enigmatic results that follow.

${ }^{25}$ Halvorsen and Palmquist [1980] note that coefficients on dummy variables should not be interpreted as the exact percentage change in log-linear regressions. However, the coefficient is extremely close to the percentage change for relatively small coefficients, as these are.

${ }^{26}$ Unlike the case of package sizes, larger advertisements correspond to higher quality.

${ }^{27}$ According to Private Label Directory, 1991. 
${ }^{28}$ A similar result is obtained if one uses market share as a measure of differentiation. Brands with higher shares discount their larger sized products more than brands with lower shares. I prefer the comparison between the branded and unbranded segments since market share is endogenous.

${ }^{29}$ I drop the first period since I do not observe the size menu in the prior period, so the maximum number of city/quarter combinations for a given brand is 1216 .

${ }^{30}$ Below, I discuss how to interpret the empirical results if one believes that firms can change their product menus instantaneously.

${ }^{31}$ Or costs may have increased less rapidly than expected.

${ }^{32}$ Everything is deterministic in Itoh's model, i.e., there are no shocks between $t$ and $t+1$.

${ }^{33}$ If it is easier to discontinue production of an existing size than to begin production of a new size, then it may not even be possible to distinguish price discrimination from pricing with independent demands when existing products are removed. Suppose it takes a period to begin producing a new size, but it takes no time to stop producing an existing size. Dropping a size would correspond to a negative shock to the brand's demand for which the first order effect results in lower prices under both of the above hypotheses. 
TABLE I: Effect of Being the Largest Size

Controlling for Absolute Size

Dependent Variable $=$ Log of Unit Price

Reported Parameter $=$ Effect of being Largest Size

\begin{tabular}{|c|c|c|c|c|c|c|c|c|}
\hline & \multicolumn{8}{|c|}{ SPECIFICATION of Absolute Size Effects } \\
\hline $\begin{array}{l}\text { SPECIFICATION of } \\
\text { Fixed Effects }\end{array}$ & \multicolumn{2}{|c|}{ Linear } & \multicolumn{2}{|c|}{$\begin{array}{l}\text { Linear, } \\
\text { By Brand }\end{array}$} & \multicolumn{2}{|c|}{$\begin{array}{c}\text { Size } \\
\text { Dummies }\end{array}$} & \multicolumn{2}{|c|}{$\begin{array}{l}\text { Size Dummies, } \\
\text { by Brand }\end{array}$} \\
\hline & Est & StdErr & Est & StdErr & Est & StdErr & Est & StdErr \\
\hline City/Time & -.1153 & .004 & -.0501 & .004 & -.1152 & .004 & & \\
\hline City/Time, Brand & .0120 & .002 & .0034 & .002 & .0119 & .002 & .0035 & .003 \\
\hline None & -.1205 & .005 & -.0778 & .004 & -.1223 & .005 & & \\
\hline Brand & -.0134 & .003 & -.0221 & .003 & -.0130 & .003 & -.0281 & .003 \\
\hline Time & -.0967 & .004 & -.0437 & .004 & -.0962 & .004 & & \\
\hline City & -.1366 & .005 & -.0848 & .004 & -.1388 & .005 & & \\
\hline Brand, Time, City & .0127 & .002 & .0044 & .002 & .0125 & .002 & .0044 & .003 \\
\hline Brand/Time, City & .0164 & .002 & .0094 & .002 & .0163 & .002 & .0112 & .002 \\
\hline Brand/City, Time & .0161 & .002 & .0064 & .002 & .0136 & .002 & .0021 & .003 \\
\hline Brand/City/Time & .0245 & .002 & .0150 & .003 & .0215 & .002 & .0165 & .003 \\
\hline
\end{tabular}

$\mathrm{N}=33,423$

Brand $/$ City $=$ Brand $/$ City Interaction

Brand, City $=$ Separate Brand and City Effects 
TABLE II: Differences in Percentage Discounts Offered for Branded and Unbranded Paper Towels

Reported Variable $=$

$\%$ Discount for Branded - \% Discount for Unbranded

Package Size

95\% Confidence Interval

(a)

Lower Bound Upper Bound

2 and 3-roll packages

$-0.078 \%$

$1.810 \%$

6-roll packages

$6.831 \%$

$8.792 \%$

$8+$ roll packages

$10.727 \%$

$13.186 \%$ 
TABLE III: Product Introductions and Removals, by Brand

\begin{tabular}{|l|c|c|c|}
\hline \multicolumn{1}{|c|}{ BRAND } & Markets & Size Introduced & Size Removed \\
\hline Bounty & 1216 & $15.46 \%$ & $14.15 \%$ \\
Brawny & 1216 & $9.87 \%$ & $5.51 \%$ \\
Mardi Gras & 1216 & $8.80 \%$ & $6.00 \%$ \\
Scottowels & 1158 & $9.24 \%$ & $19.17 \%$ \\
Hi Dri & 1213 & $8.74 \%$ & $11.05 \%$ \\
Sparkle & 1180 & $10.59 \%$ & $2.54 \%$ \\
Kleenex Viva & 576 & $19.10 \%$ & $6.60 \%$ \\
Marcal & 615 & $11.55 \%$ & $10.89 \%$ \\
Scott Clean & 318 & $22.96 \%$ & $5.66 \%$ \\
So Dri & 1172 & $0.00 \%$ & $0.17 \%$ \\
Coronet & 564 & $8.69 \%$ & $1.42 \%$ \\
Coronet Big N Thirsty & 415 & $4.34 \%$ & $7.47 \%$ \\
Green Forest & 1044 & $0.00 \%$ & $0.00 \%$ \\
Zee & 418 & $6.46 \%$ & $8.37 \%$ \\
Versatile Viva & 362 & $4.97 \%$ & $11.05 \%$ \\
Bounty Rinse \& Reuse & 436 & $5.96 \%$ & $1.38 \%$ \\
Viva Ultra & 317 & $14.51 \%$ & $1.58 \%$ \\
\hline
\end{tabular}


TABLE IV: Effect of Changes in Product Menus on Prices

Dependent Variable $=\left(\mathbf{P}_{\mathrm{i}, \mathrm{t}+1}-\mathbf{P}_{\mathrm{i}, \mathrm{t}}\right) / \mathbf{P}_{\mathrm{i}, \mathrm{t}}$

\begin{tabular}{|c|c|c|c|c|c|c|c|c|c|c|c|c|}
\hline \multirow{3}{*}{ REGRESSORS } & \multicolumn{12}{|c|}{ SPECIFICATIONS: Comparison of products with same ... } \\
\hline & \multicolumn{2}{|c|}{ Brand } & \multicolumn{2}{|c|}{$\begin{array}{c}\text { Brand/ } \\
\text { Time }\end{array}$} & \multicolumn{2}{|c|}{$\begin{array}{c}\text { Brand/ } \\
\text { City }\end{array}$} & \multicolumn{2}{|c|}{$\begin{array}{c}\text { Brand/ } \\
\text { Number } \\
\text { of Rolls }\end{array}$} & \multicolumn{2}{|c|}{$\begin{array}{c}\text { Brand/Time/ } \\
\text { Number } \\
\text { of Rolls }\end{array}$} & \multicolumn{2}{|c|}{$\begin{array}{c}\text { Brand/City/ } \\
\text { Number } \\
\text { of Rolls }\end{array}$} \\
\hline & Est & StdErr & Est & StdErr & Est & StdErr & Est & StdErr & Est & StdErr & Est & StdErr \\
\hline Avg of Fixed Effects & .0138 & .0007 & .0142 & .0007 & .0138 & .0007 & .0138 & .0007 & .0145 & .0006 & .0137 & .0007 \\
\hline Any Size Added & -.0072 & .0045 & -.0037 & .0045 & -.0075 & .0046 & -.0050 & .0045 & -.0043 & .0048 & -.0062 & .0049 \\
\hline Any Size Dropped & -.0041 & .0043 & -.0054 & .0042 & -.0040 & .0044 & -.0029 & .0043 & -.0041 & .0043 & -.0024 & .0047 \\
\hline Larger Size Added & .0244 & .0049 & .0180 & .0048 & .0253 & .0050 & .0221 & .0050 & .0147 & .0052 & .0246 & .0053 \\
\hline Larger Size Dropped & .0030 & .0049 & .0015 & .0048 & .0034 & .0050 & .0010 & .0050 & -.0004 & .0049 & .0017 & .0054 \\
\hline
\end{tabular}

$\mathrm{N}=29,879$

Price $=\$$ per 100 square feet 